\title{
Бинарные отношения между факторами недревесной продукции леса Бугульминско-Белебеевской возвышенности Башкирии
}

Хисамов Р.Р., Мазуркин П.М., Рахматуллина И.Р.

Введение. Бугульминско-Белебеевская возвышенность в пределах Республики Башкортостан занимает западную приподнятую окраину и является одним из промышленно развитых, густонаселенных и лесодефицитных районов (рис. 1). По лесорастительному районированию территория отнесена к лесостепной зоне и лесостепному району Европейской части Российской Федерации.

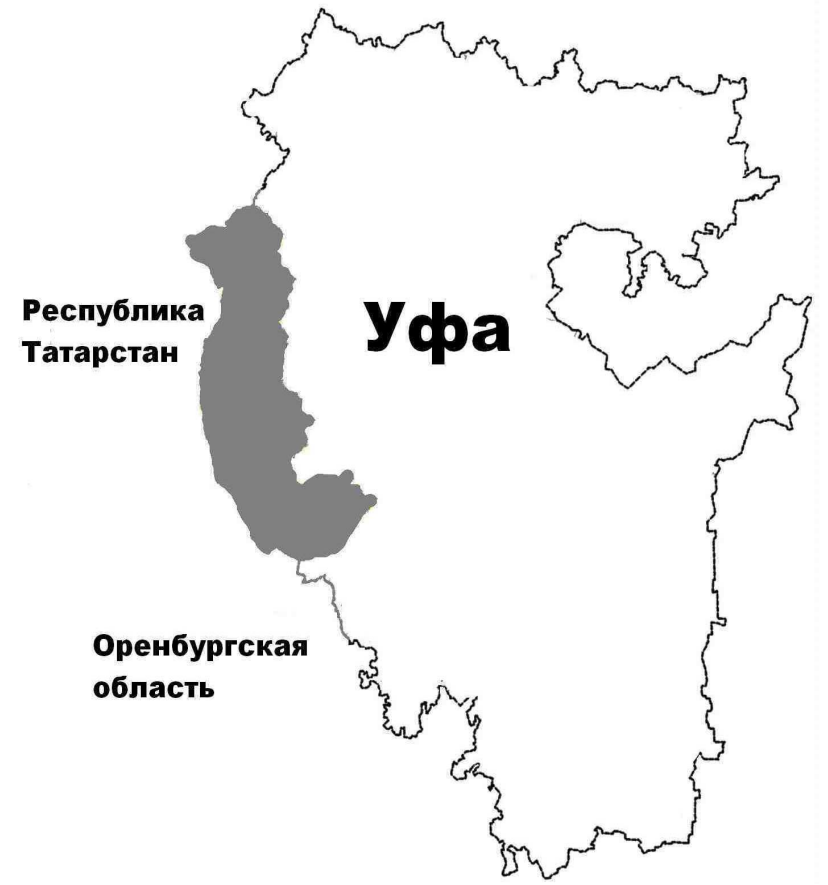

Рисунок 1. Бугульминско-Белебеевская возвышенность в пределах территории Республики Башкортостан

Исходные данные выбирались из годовых отчетов лесничеств за 8 лет (2006-2013 гг.) [6, 7]. Поэтому эти данные показывают средние значения показателей за период в восемь лет.

Факторный анализ в общем случае проводится в четыре этапа:

1) выявление закономерностей рангового распределения по факторам;

2) выявление биотехнических закономерностей бинарных отношений между учитываемыми факторами;

3) рейтинг учтенных факторов по строкам (факторы как влияющие переменные) и столбцам (факторы как зависимые показатели) по общей корреляционной матрице;

4) рейтинг бинарных отношений по коэффициенту корреляции.

В статье покажем методику по второму этапу - моделирование идентификацией устойчивых законов [1-5].

Концепция моделирования. Подробнее отдельные особенности предложенной методологии даны в монографии [1]. Технология пользования программной средой CurveExpert показана в пособии [5].

Идентификация по числовому полю или табличной модели имеет этапы:

1) эвристическая идентификация сути изучаемого явления или процесса по результатам измерений и анализа табличной модели (априорная информация) и осмысления в ходе выявления конструкции у однофакторной закономерности по её аддитивным составляющим (апостериорная информация);

2) структурная идентификация каждой однофакторной математической (статистической) функции как суммы инвариантов в виде асимметричных вейвлет-сигналов с переменными амплитудой и периодом колебания;

3) параметрическая идентификация наращиваемой по отдельным инвариантам структуры устойчивой статистической закономерности в программной среде типа CurveExpert (http://www.curveexpert.net). 
Идентификация эвристическая. Она предполагает знание предмета исследования, поэтому здесь важен переход от физики к математике, а не наоборот. Главное эвристическое значение приобретает заданное числовое поле, как правило, оформляемое по результатам измерений в виде таблицы. В ней неявно заключен весь содержательный смысл (эвристика) и понимание (концепция) автора измерений, то есть сущностный смысл эксперимента.

Мы давно отказались от методологии аппроксимации и, соответственно, вообще не применяем программы статистики из Excel. В идентификации первый этап (вариация функций) из теории аппроксимации исключается, - устойчивые законы заранее заданы как инварианты. Из них как из кирпичиков можно создавать различные математические конструкты. Использование в каждом конкретном примере статистического (вероятностного) моделирования того или иного устойчивого закона (по таблице 1 их всего семь) требует предварительного эвристического осмысления содержания задачи моделирования.

Таким образом, на эвристическом уровне 23-я проблема Гильберта нами пока недостаточно формализована. Но проблема развития методов вариационного исчисления была решена на структурном и параметрическом уровнях анализа и синтеза. Вариация функций сводится к осознанному отбору устойчивых законов и конструированию на их основе волновых закономерностей.

Идентификация структурная. Декарт предполагал существование одного-единственного алгебраического уравнения, пригодного как вариант решения для любых типов интегральных уравнений. Гильберт мечтал об инвариантах, из них как из кирпичиков будет собираться универсальное уравнение.

Наши универсальные инварианты даны в таблице 1.

Таблица 1

Математические конструкты (исходные инварианты

или кирпичики Гильберта) для составления статистической модели

\begin{tabular}{|c|c|}
\hline $\begin{array}{c}\text { Фрагменты без предыстории } \\
\text { изучаемого явления или процесса }\end{array}$ & $\begin{array}{c}\text { Фрагменты с предысторией } \\
\text { изучаемого явления или процесса }\end{array}$ \\
\hline $\begin{array}{l}y=a x \text { - закон линейного роста или спада (при } \\
\text { отрицательном знаке перед правой стороной фор- } \\
\text { мулы линейного изменения) }\end{array}$ & $\begin{array}{l}y=a-\text { закон не влияния принятой объясняющей } \\
\text { переменной на показатель, который имеет собст- } \\
\text { венную предысторию значений }\end{array}$ \\
\hline $\begin{array}{l}y=a x^{b} \text { - закон показательного роста (закон пока- } \\
\text { зательной гибели } y=a x^{-b} \text { не является устойчи- } \\
\text { вым, из-за бесконечности значения показателя } \\
\text { при нулевом значении объясняющей переменной) }\end{array}$ & $\begin{array}{l}y=a \exp ( \pm c x) \text { - закон Лапласа в математике } \\
\text { (Ципфа в биологии, Парето в экономике, Ман- } \\
\text { дельброта в физике) экспоненциального роста или } \\
\text { гибели, относительно которого } \\
\text { Лаплас создал методологию операторного исчис- } \\
\text { ления }\end{array}$ \\
\hline $\begin{array}{l}y=a x^{b} \exp (-c x) \text { - биотехнический закон в уп- } \\
\text { рощенной форме (П.М. Мазуркин), когда показа- } \\
\text { тельный рост постепенно получает экспоненци- } \\
\text { альное торможение }\end{array}$ & $\begin{array}{l}y=a \exp \left( \pm c x^{d}\right) \text { - закон экспоненциального рос- } \\
\text { та или гибели в полной форме (конструкции), } \\
\text { который имеет интенсивность, не равную единице } \\
\text { (П.М. Мазуркин) }\end{array}$ \\
\hline \multicolumn{2}{|c|}{$y=a x^{b} \exp \left(-c x^{d}\right)$ - биотехнический закон, общий для шести конструктов (П.М. Мазуркин) } \\
\hline
\end{tabular}

Они сгруппированы по принципу «от простого к сложному». По сути, фрагменты и сам биотехнический закон являются «кирпичиками Гильберта» для построения, в ходе процесса структурно-параметрической идентификации, аддитивной конструкции статистической модели с трендами и вейвлетами. 
В таблице 1 показаны наиболее встречающиеся инварианты (фрагменты). У них впереди могут быть расположены оперативные константы «+» или «-». Шесть устойчивых законов распределения являются частными случаями биотехнического закона, показанного внизу таблицы 1. В названии закона слово «биотехнический» означает, что мы придерживаемся идей В.И. Вернадского о космической функции жизни.

Устойчивые законы и закономерности на их основе делают выбор уравнения для последующей идентификации на статистических данных (числовых полях) вполне осмысленным, и поэтому вероятностное моделирование остается только при случайном поиске программной средой типа CurveExpert значений параметров у искомой модели. Поэтому из теории идентификации первый этап (выбор случайной структуры уравнения) исключается и остается только второй этап - случайная идентификация значений параметров модели.

Структура модели идентифицируется обработкой исходных данных так:

- вначале выявить детерминированные нелинейные закономерности;

- затем дополнять эти тренды колебательными возмущениями.

Идентификация параметрическая. Она выполнялась в программной среде CurveExpert-1.40 (http://www.curveexpert.net) и информационной технологией идентификации пользуются студенты (будущие бакалавры и магистры), а также аспиранты и докторанты. На сквозных примерах методология структурно-параметрической идентификации подробно показана в книгах [1-5].

Процесс параметрической идентификации автоматически прекращается по условию достижения параметров модели некоторого минимального приращения и останавливается при достижении моделью погрешности измерений.

В таблице 2 приведены интервалы изменения коэффициента корреляции.

Уровни адекватности статистических моделей

\begin{tabular}{|c|c|c|c|c|}
\hline \multirow{2}{*}{$\begin{array}{c}\text { Интервал коэф- } \\
\text { фициента } \\
\text { корреляции }\end{array}$} & \multicolumn{4}{|c|}{ Характер тесноты связи между факторами } \\
\hline & $\begin{array}{l}\text { существующая } \\
\text { классификация }\end{array}$ & $\begin{array}{c}\text { шкала для } \\
\text { технических } \\
\text { измерений } \\
\end{array}$ & \begin{tabular}{|c|} 
шкала для \\
прецизионных \\
измерений \\
\end{tabular} & $\begin{array}{c}\text { шкала для генной } \\
\text { инженерии и рядов це- } \\
\text { лых простых чисел }\end{array}$ \\
\hline 1 & \multirow{6}{*}{ сильная связь } & однозначная & однозначная & однозначная \\
\hline $0.999 \ldots 1.0000$ & & \multirow{4}{*}{ сильнейшая } & \multirow{2}{*}{ почти однозначная } & почти однозначная \\
\hline $0,99 \ldots 1,000$ & & & & чрезвычайно сильная \\
\hline $0,95 \ldots 0,99$ & & & сверхсильная & сверхсильная \\
\hline $0,90 \ldots 0,95$ & & & сильнейшая & сильнейшая \\
\hline $0,7 \ldots 0,9$ & & сильная & сильная & сильная \\
\hline $0,5 \ldots 0,7$ & \multirow{2}{*}{ слабая связь } & средняя & средняя & средняя \\
\hline $0,3 \ldots 0,5$ & & слабоватая & слабоватая & слабоватая \\
\hline $0,1 \ldots 0,3$ & \multirow{3}{*}{ нет связи } & слабая & Слабая & слабая \\
\hline $0,0 \ldots 0,1$ & & слабейшая & слабейшая & слабейшая \\
\hline 0 & & нет связи & нет связи & нет связи \\
\hline
\end{tabular}

Существующая шкала квантификации тесноты связи между принятыми факторами (нет связи, слабая и сильная связь) является очень грубой.

Критерием (количественной мерой) идентификации становится погрешность измерений при составлении числового поля, т.е. таблицы исходные дан- 
ных. Например, простые числа и их ряды не имеют погрешности измерения: они абсолютно достоверны, добротны и надежны. Другие виды исходных данных имеют разную погрешность. Таким образом, математические числовые объекты - наилучшие для идентификации законов-инвариантов.

На втором месте находятся прецизионные измерения в астрономии, физике, технике и технологии, других областях науки. На третье место встают биологические объекты (у нас - почва [2] и деревья [3]), и их поведение имеет четко проявляющийся колебательный характер, поэтому линейные и линеаризованные модели биологам вообще не подходят. Самые высокие погрешности имеют социально-экономические измерения из-за их субъективности.

Анализ литературы по математической статистике показал, что в аппроксимации сплошь и рядом применяется линейная модель или же не имеющий физического смысла алгебраический полином. Это происходит из-за того, что линейная модель инвариантна к любому типу распределения и отрицательным значениям объясняющей переменной, в том числе и явно негауссовой структуры, и даже к скедастическим [1] данным измерений с переменной дисперсией.

Нами предложена для технических экспериментов, в которых погрешность измерений не превышает 5\%, другая шкала (третий столбец таблицы 2). Однако выяснилось, что этой шкалы адекватности также недостаточно.

Для многих природных (биологических) объектов и результатов прецизионных физических измерений пришлось ввести еще два интервала уровня адекватности по четвертому столбцу таблицы 2, что нами было выполнено только при моделировании распределений рядов простых чисел [1]. А для генной инженерии пришлось ввести еще один уровень адекватности, который нами был открыт только для рядов целых простых чисел.

Концепция моделирования по статистическим выборкам. Статистическая выборка - это многофакторное числовое поле в виде табличной модели. Этим определением она отличается от таблиц статистических изысканий. Причем необязательно все клетки таблицы должны быть заполненными.

При этом табличная модель необязательно имеет эвристические пояснения. Как правило, авторы измерений, приводя в своих публикациях таблицы данных, дают неверные содержательные толкования. Этот феномен эвристической формализации связан с тем, что таблица результатов измерений, даже если она составлена авторами правильно, не может быть содержательно осмыслена без проведения факторного анализа с математическим моделированием связей между парами факторов для выявления бинарных связей.

Тогда первичной становится табличная модель (исходное числовое поле), которая оценивается по погрешности проведенных измерений, а вторичным является искомое сложное алгебраическое уравнение (в смысле Декарта), составленное из инвариантов таблицы 1 (в смысле кирпичиков Гильберта). Этот процесс есть статистическая идентификация. Сама первообразная в виде неизвестного интегрального уравнения становится не нужным, хотя, может быть, кто-то и сумеет получать интегралы по нашим моделям.

Это - великое созидание, как уравнения Максвелла в электромагнетизме.

Детерминированная модель. В общем случае не волновая модель 
(тренд) содержит сумму двух биотехнических законов в виде уравнения

$$
y_{m}=y_{m 1}+y_{m 2}, y_{m 1}=a_{1} x^{a_{2}} \exp \left(-a_{3} x^{a_{4}}\right), y_{m 2}=a_{5} x^{a_{6}} \exp \left(-a_{7} x^{a_{8}}\right),
$$

где $y_{m}$ - тренд показателя, $x$ - объясняющая переменная, $a_{1} \ldots a_{8}$ - параметры модели (1), получаемые в CurveExpert (URL: http://www.curveexpert.net/).

При этом каждый параметр модели (1) имеет физический смысл $[1,5]$.

Не волновой характер общая модель (1) получает в двух случаях:

1) когда шаг дискретности измерений слишком большой по сравнению с периодом колебательного возмущения измеряемого реального процесса (например, импульс электрокардиограммы требует регистрации через 0,001 с);

2) когда интервал процесса измерений мал по сравнению с полупериодом колебательного возмущения измеряемого показателя (например, среднегодовая температура в точке Земли требует регистрации за 1000 лет и более).

Исходные данные. Табличные данные для статистического моделирования $[6,7]$ даны в таблице 3 и таблице 4.

Таблица 3

Распределение земель по районам на Бугульминско-Белебеевской возвышенности по категориям земель, тыс.га

\begin{tabular}{|c|c|c|c|c|c|c|c|c|c|}
\hline \multirow[b]{2}{*}{ Район } & \multirow[b]{2}{*}{$\begin{array}{c}\text { Общая } \\
\text { площадь } \\
S\end{array}$} & \multirow{2}{*}{$\begin{array}{c}\text { Земли сельско- } \\
\text { хозяйственного } \\
\text { назначения } \\
S_{c x y}\end{array}$} & \multicolumn{6}{|c|}{ Земли лесного фонда } & \multirow[b]{2}{*}{$\begin{array}{c}\text { Прочие } \\
\text { земли } \\
S_{n p}\end{array}$} \\
\hline & & & $\begin{array}{c}\text { песопок- } \\
\text { рытые } \\
S_{л n}\end{array}$ & $\begin{array}{c}\text { ре- } \\
\text { дины } \\
S_{p}, \text { га }\end{array}$ & $\begin{array}{c}\text { вы- } \\
\text { рубки } \\
S_{\beta}, \text { га }\end{array}$ & $\begin{array}{l}\text { прога- } \\
\text { лины } \\
S_{n p}, \text { га } \\
\end{array}$ & $\begin{array}{c}\text { сено- } \\
\text { косы } \\
S_{c}\end{array}$ & $\begin{array}{c}\text { паст- } \\
\text { бища } \\
S_{n}\end{array}$ & \\
\hline ака & & 119.70 & 59.930 & 39 & 1063 & 176 & 1.543 & 1.011 & 11.4 \\
\hline Бель & & & & 65 & 889 & 279 & 1.328 & 1.046 & \\
\hline Бижбул & & & & 91 & 276 & 381 & 0.707 & 0.524 & \\
\hline Ермеке & & & & 15 & 94 & 104 & 0.415 & 0.510 & \\
\hline Мияк & & & & 104 & 265 & 214 & 1.195 & 0.636 & 14.396 \\
\hline Туйма & & & & 97 & 1186 & 524 & 2.669 & 1.545 & 24.577 \\
\hline Шаранский & 138.42 & 95.75 & 33.780 & 24 & 431 & 50 & 0.423 & 0.403 & 7.548 \\
\hline
\end{tabular}

Таблица 4

Показатели заготовки побочной продукции леса по районам на Бугульминско-Белебеевской возвышенности

\begin{tabular}{|c|c|c|c|c|c|c|c|c|}
\hline Район & $\begin{array}{c}\text { Площадь } \\
\text { лесного } \\
\text { фонда } \\
S_{\text {ЛФ }} \text {, тыс. } \\
\text { га }\end{array}$ & $\begin{array}{c}\text { Площадь } \\
\text { липня- } \\
\text { ков } \\
S_{Л}, \text { тыс. га }\end{array}$ & $\begin{array}{c}\text { Объем } \\
\text { рубок } \\
\text { ухода } \\
Q_{P y}, \text { тыс. }{ }^{3}\end{array}$ & $\begin{array}{c}\text { Объем } \\
\text { заготовки } \\
\text { плодов } \\
\text { и ягод } \\
Q_{\text {Пя }}, \text { ц }\end{array}$ & $\begin{array}{c}\text { Объем } \\
\text { заготовки } \\
\text { лекарств. } \\
\text { сырья } \\
Q_{\text {ЛС }}, \text { ц }\end{array}$ & $\mid \begin{array}{c}\text { Валовой } \\
\text { выход } \\
\text { сена } \\
Q_{C}, \text { т }\end{array}$ & $\begin{array}{c}\text { Объем } \\
\text { медо- } \\
\text { сбора } \\
Q_{m}, \text { т }\end{array}$ & $\begin{array}{c}\text { Кол-во } \\
\text { пчело } \\
\text { семей } \\
N_{\Pi C}, \\
\text { шт. }\end{array}$ \\
\hline Бакалинский & 63.894 & 19.120 & 29.9104 & 78.03 & 6.65 & 465.444 & 71.898 & 3121 \\
\hline Белебеевский & 68.816 & 11.859 & & 50.99 & 6.18 & 243.150 & & 1901 \\
\hline Бижбулякский & 34.499 & 0.568 & 9.1416 & 21.50 & 4.61 & 138.300 & 30.379 & 1218 \\
\hline Ермекеевский & 21.738 & 13.072 & 6.7686 & 10.74 & 3.43 & 802.200 & 59.563 & 2006 \\
\hline Миякин & 39.909 & 8.550 & 10.9030 & 20.50 & 3.76 & & 43.479 & 1519 \\
\hline Туймазинский & 74.431 & 25.012 & & 66.40 & 10.50 & 325.767 & 477 & 2143 \\
\hline Шаранский & 35.118 & 8.440 & 10.9427 & 12.48 & 2.47 & 150.800 & 32.696 & 1378 \\
\hline
\end{tabular}

Bсе 17 факторов принимаются одновременно за объясняющие переменные и зависимые показатели. Тогда можно для каждой объясняющей переменной выявлять группу зависимых показателей, то выявить бинарные связи. 
Для примера в статье примем влияние площади липняков. Этот фактор как влияющая переменная занял первое место в рейтинге.

Влияние площади липняков. Результаты статистического моделирования приведены на рисунках 2 и 3, а параметры модели (1) даны в таблице 5.
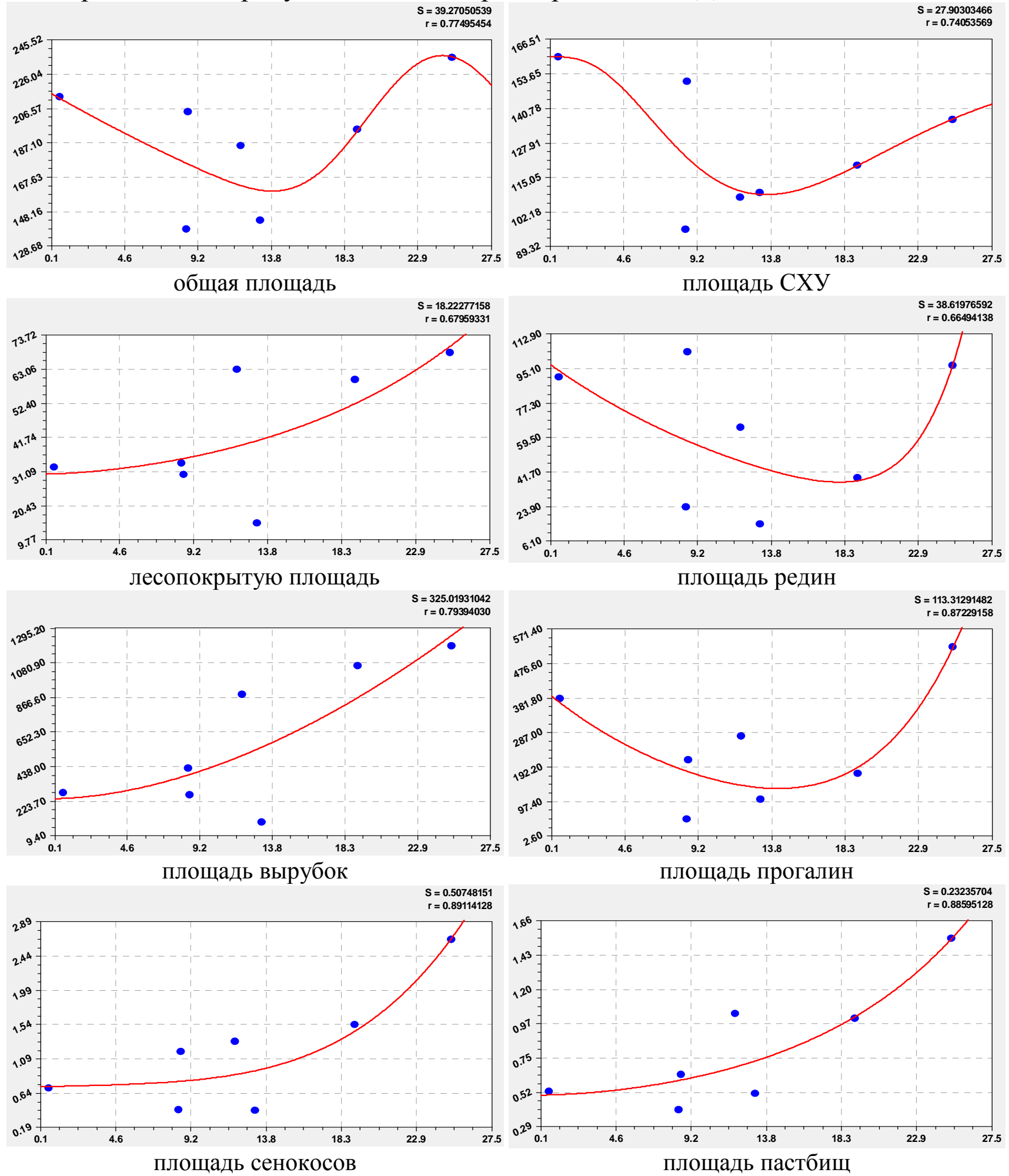

Рисунок 2. Графики влияния площади липняков на остальные факторы

По формулам в программной среде можно провести прямые расчеты и определить оптимальные значения площади липняков для условий Бугульминско-Белебеевской возвышенности для достижения максимума объемов недре- 
весной продукции. Из графиков на рисунке 2, например, видно, что площади района и сельскохозяйственных угодий должны быть минимальными.
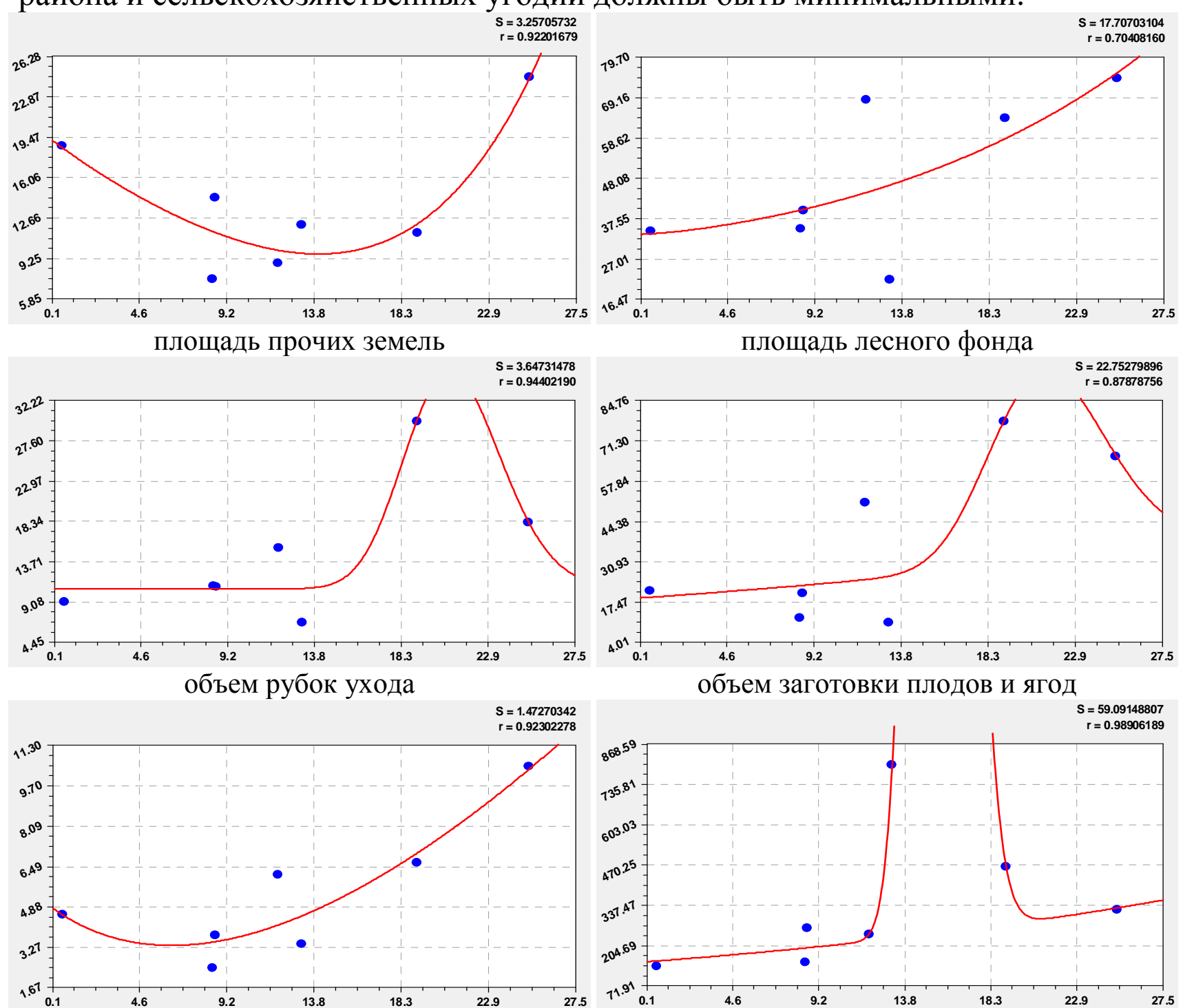

объем заготовки лекарственного сырья

$\mathrm{S}=5.18085899$
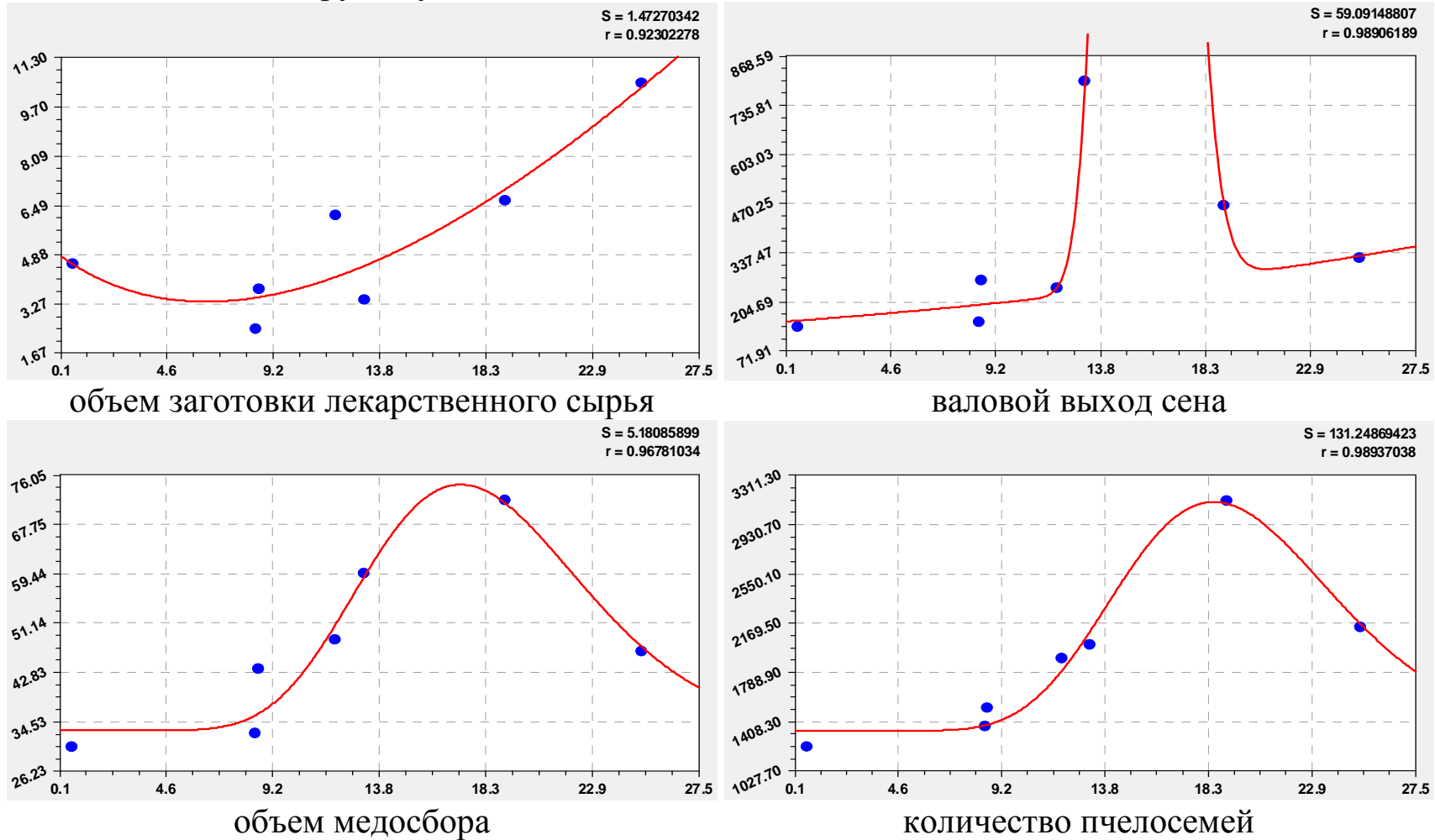

валовой выход сена

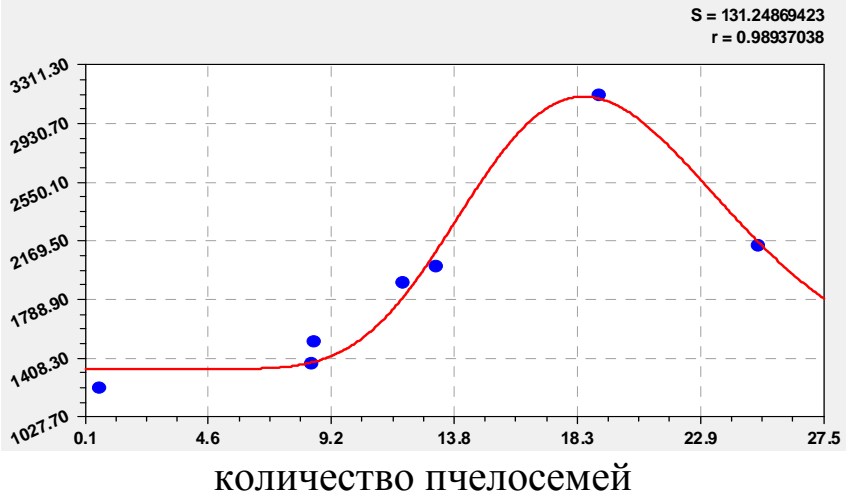

Рисунок 3. Графики влияния площади липняков на остальные факторы

При этом площади редин и прогалин должны быть минимальными, что потребует новых посадок лесных деревьев. Кроме того, лесопокрытая площадь в любом районе должна быть не менее 52,4 тыс. га. Это позволит увеличить площади вырубок до 900 га, а в Бакалинском и Туймазинском районах, наоборот, снизить площадь вырубок до 900 га. Для этого оптимальная площадь лип- 
няков в каждом районе должна быть в пределах 18-19 тыс. га. Это одновременно позволит повысить площади сенокосов до 1,5 и пастбищ до 1,0 тыс. га.

Таблица 5

Параметры закономерностей влияния площади липняков на остальные факторы

\begin{tabular}{|c|c|c|c|c|c|c|c|c|c|c|}
\hline \multirow{3}{*}{$\begin{array}{c}\text { № } \\
\Pi / \Pi\end{array}$} & \multirow{3}{*}{$\begin{array}{c}\text { По- } \\
\text { каза- } \\
\text { тель } \\
y\end{array}$} & \multicolumn{8}{|c|}{$y=a_{1} x^{a_{2}} \exp \left(-a_{3} x^{a_{4}}\right)+a_{5} x^{a_{6}} \exp \left(-a_{7} x^{a_{8}}\right)$} & \multirow{3}{*}{$\begin{array}{c}\text { Коэф. } \\
\text { корр. } \\
r\end{array}$} \\
\hline & & \multicolumn{4}{|c|}{ Первая составляющая } & \multicolumn{4}{|c|}{ Вторая составляющая } & \\
\hline & & $a_{1}$ & $a_{2}$ & $a_{3}$ & $a_{4}$ & $a_{5}$ & $a_{6}$ & $a_{7}$ & $a_{8}$ & \\
\hline 1 & $S$ & 215,32949 & 0 & 0,024125 & 1 & $1,56504 \mathrm{e}-18$ & 20,57645 & 0,81849 & 1 & 0,7750 \\
\hline 2 & $S_{c x y}$ & 160,07633 & 0 & 0,00048122 & 1 & $-0,17953$ & 3,53529 & 0,26402 & 1 & 0,7405 \\
\hline 3 & $S_{л n}$ & 30,38230 & 0 & $-0,0046236$ & 1,61548 & 0 & 0 & 0 & 0 & 0,6796 \\
\hline 4 & $S_{p}$ & 97,36860 & 0 & 0,061005 & 1 & $3,05921 \mathrm{e}-11$ & 8,86509 & 0 & 0 & 0,6649 \\
\hline 5 & $S_{6}$ & 241,28436 & 0 & 0 & 0 & 3,27136 & 1,78022 & 0 & 0 & 0,7939 \\
\hline 6 & $S_{n p}$ & 388,96880 & 0 & 0,091751 & 1 & $4,75784 \mathrm{e}-5$ & 5,01068 & 0 & 0 & 0,8723 \\
\hline 7 & $S_{c}$ & 0,72389 & 0 & $-0,0077315$ & 1 & $4,62428 \mathrm{e}-6$ & 3,99910 & 0 & 0 & 0,8911 \\
\hline 8 & $S_{n}$ & 0,50017 & 0 & $-0,0047451$ & 1,69891 & 0 & 0 & 0 & 0 & 0,8859 \\
\hline 9 & $S_{n p}$ & 19,26024 & 0 & 0,062655 & 1 & $1,62280 \mathrm{e}-5$ & 4,36323 & 0 & 0 & 0,9220 \\
\hline 10 & $S_{\text {ЛФ }}$ & 33,50749 & 0 & $-0,0083731$ & 1,42221 & 0 & 0 & 0 & 0 & 0,7041 \\
\hline 11 & $Q_{P Y}$ & 10,61278 & 0 & 0 & \begin{tabular}{|l|}
0 \\
\end{tabular} & $1,43572 \mathrm{e}-59$ & 68,02428 & 3,25695 & 1 & 0,9440 \\
\hline 12 & $Q_{\text {Пя }}$ & 18,84074 & 0 & $-0,023593$ & 1 & $6,77214 \mathrm{e}-42$ & 48,07296 & 2,25832 & 1 & 0,8788 \\
\hline 13 & $Q_{Л C}$ & 4,85920 & 0 & 0,11895 & 1 & 0,051696 & 1,63887 & 0 & 0 & 0,9230 \\
\hline 14 & $Q_{C}$ & 151,87939 & 0 & $-0,030944$ & 1 & $8,52351 \mathrm{e}-116$ & 156,52094 & 10,02313 & 1 & 0,9891 \\
\hline 15 & $Q_{m}$ & 33,11628 & 0 & 0 & 0 & $4,58937 \mathrm{e}-10$ & 13,66218 & \begin{tabular}{|l|}
0,79324 \\
\end{tabular} & 1 & 0,9678 \\
\hline 16 & $N_{\Pi C}$ & 1338,7847 & 0 & 0 & 0 & $3,12272 \mathrm{e}-10$ & 15,29863 & 0,82556 & 1 & 0,9894 \\
\hline
\end{tabular}

Из графиков на рисунке 3 видно, что площадь прочих земель должна быть не более 9,0 тыс. га, при этом площадь лесного фонда не менее 55,0 тыс. га, а объем лекарственно сырья - не менее 6,5 ц. При таких условиях будет обеспечен максимальный выход продукции: объем заготовки плодов и ягод не менее 85 ц, валовой выход сена не менее 1000,0 т, объем заготовки мёда более 75 т при количестве пчелосемей не менее 3050 шт. Леса на БугульминскоБелебеевской возвышенности в каждом из семи районов нужно будет улучшать рубками ухода, при этом заготовляя древесного сырья не менее 65,0 тыс. м $^{3}$.

Заключение. Статистическое моделирование позволяет выявить высокоадекватные тренды, а при количестве районов более 20 и с дополнительными волновыми составляющими, взаимной зависимости вышеприведенных 17 факторов. Результаты моделирования влияния площади липняков показывают, что их площадь в каждом районе нужно увеличивать до не менее 18-19 тыс. га. Это позволит увеличить максимальное количество продукции леса, включая и древесное сырье рубками ухода.

\section{Список литературы:}

1. Мазуркин П.М. Статистическое моделирование. Эвристикоматематический подход. Йошкар-Ола: МарГТУ, 2001. 100с.

2. Мазуркин П.М. Коррелятивная вариация: учеб. пос. с грифом УМО РАЕ. Йошкар-Ола: Поволжский ГТУ, 2013. 120 с. 
3. Мазуркин П.М. Биокаркас территории: учеб. пос. с грифом УМО РАЕ. Йошкар-Ола: Поволжский ГТУ, 2013. 156 с.

4. Мазуркин П. М., Михайлова С.И. Территориальное экологическое равновесие $=$ Territprial ecological balance: аналит. обзор; Учреждение Рос. акад. наук Гос. публич. науч.-техн. б-ка Сиб. отд-ния РАН. Новосибирск: ГПНТБ СО РАН, 2010. 430 с. (Сер. Экология. Вып. 94).

5. Мазуркин П.М., Филонов А.С. Математическое моделирование. Идентификация однофакторных статистических закономерностей: учеб. пос. Йошкар-Ола: МарГТУ, 2006. 292 с.

6. Хисамов Р.Р. Хозяйственно-ценный фитоценоз в защитных лесных насаждениях на агроландшафтах Белебеевской возвышенности Республики Башкортостан / Хисамов Р.Р., Рахматуллина И.Р., Рахматуллин 3.З., Хасанов Ф.Ф. // Материалы международной научно-практической конференции «Сберегающие (биологическое) земледелие в современном сельском хозяйстве». Уфа: Гилем, Башк.энцикл., 2014. 244 с.

7. Хисамов Р.Р., Кулагин А.А. Биологические ресурсы Республики Башкортостан: недревесные ресурсы леса. Уфа: Изд-во БГПУ, 2014. 292 с. 